\title{
VELHOS MODELOS PRODUTIVOS E REESTRUTURAÇÃO FORDISTA NA INDUSTRIA, NO BAIXO JAGUARIBE, CEARÁ
}

\author{
Prof. Msc. Edilson Pereira Júnior \\ Departamento de Geociências da Universidade Estadual do Ceará - UECE \\ Doutorando do Programa de Pós-Graduação da UNESP. Presidente Prudente \\ Mário Bôscoli, 205. Apto 31. CEP 19.060-540. Jardim Icaray. Presidente Prudente-SP (SP) - Brasil \\ Tel.: (55 85) 3101.9762 - edilsonapjr@hotmail.com
}

\begin{abstract}
RESUMO
A organização do processo produtivo industrial na região do Baixo Jaguaribe, no Ceará, é marcada por duplo perfil, no qual é possível depararmos com a presença de arranjos produtivos locais, assim como, com investimentos de capital exterior, atraídos a partir de uma série de benefícios, em especial os incentivos fiscais e a força de trabalho a baixo custo. Na medida em que expressa crescimento econômico e redistribui uma gama de atividades, o processo redefine o papel da região, remetendo à organização territorial um conjunto de articulações definidas em função das relações de submissão, centralidade e comando frente ao Estado, concretizadas em diferentes escalas a partir de um intenso fluxo de pessoas e objetos. O presente trabalho objetiva discutir tais questões, realizando um exercício crítico de interpretação através de componentes apreendidos a partir de uma validação empírica, considerando também o olhar teórico sobre a resistência e/ou a mobilidade dos capitais, no contexto das transformações políticas e econômicas nestes tempos de mundialização.
\end{abstract}

Palavras-chave: Atividade industrial, novos e velhos modelos produtivos, região do Baixo Jaguaribe (CE).

\begin{abstract}
The organization of the productive process in Baixo Jaguaribe, in Ceará, is marked by double profile, where you can meet up with the presence of both traditional types of regional industry, as modern investment of foreign capital attracted by a number of benefits, especially to fiscal incentives and workforce at low cost. To the extent that expresses economic growth and redistribute a range of activities, the process redefine the role of the region, referring to the territorial organization a set of joints defined in terms of the submission relationships, centrality command from the State, implemented at different scales from an intense flow of people and objects. This paper aims to discuss such issues, performing a critical exercise of interpretation through components seized from an empirical validation, also considering the theoretical point of resistance and / or the mobility of capital in the context of political and economical changes in these times of globalization.
\end{abstract}

Key words: Industrial activity, new and old production models, the region of Baixo Jaguaribe (CE).

\section{RÉSUMÉ}

L'organisation de la production industrielle dans la région du Baixo Jaguaribe dans l'Etat du Ceará, est marquée par un double profil, où on est possible faire face à la présence de l'industrie traditionnelle et de l'industrie moderne, ça dernière, formé de capitaux étrangers, attirés par un certain nombre d'avantages. Dans la mesure où ont exprimé la croissance économique, le procès redéfi le rôle de la région et sa l'organisation territoriale, mis en œuvre en différentes échelles une intense circulation des personnes et des marchandises. Cet article discute ces questions. Ses objectifs sont de réaliser un exercice d'interprétation à partir des éléments d'une validation empirique, en considérant aussi l'aspect théorique de la mobilité du capital dans le contexte des transformations politiques et économiques, en ces temps de mondialisation.

Mots-Clés: Activité industrielle, nouveaux et les anciens modèles de la production, région du Baixo Jaguaribe (CE).

\section{INTRODUÇ̃̃O}

Novos investimentos industriais encontram problemas para selecionar, entre as alternativas possíveis, a melhor definição do local onde se instalará uma unidade de produção. Nesta seleção influem, além dos custos e eficiência dos transportes, a proximidade de um mercado dinâmico, o custo de energia e água, o preço do terreno, entre outros. Mas interpretar a escolha locacional de determinada empresa somente por estes fatores significa trabalhar numa perspectiva na qual o mercado é livre e ausente de ações político-econômicas conjunturais. É uma observação que ignora as práticas sociopolíticas e as estruturas históricas (CAMAGNI, 2005; KON, 1999).

Isso não significa que uma abordagem diferente venha a desconsiderar o papel das variáveis apresentadas inicialmente. Muitas vezes, é o processo de produção e distribuição da indústria que vai 
determinar sua localização e, quando isso acontece, é a própria empresa que decide ter ou não uma alocação orientada pelos referenciais de transporte, força de trabalho ou outro fator mais decisivo.

Quando tratamos dessas questões num país como o Brasil e, em especial, numa região como o Nordeste, a complexidade dos elementos na leitura socioespacial requer que ações político-econômicas sejam consideradas, sob pena de não apreendermos a abrangência dos fatores envolvidos no processo. Há algumas décadas a discussão sobre industrialização no Nordeste perpassa pela análise do desenvolvimento regional, o que concede à indústria caráter de discussão político-governamental. A participação dos governos pode ser observada, nesse sentido, como um dos instrumentos indispensáveis na atração de investimentos ligados às empresas industriais. Em alguns casos concebe importância menor a outros fatores destacados pelas teorias tradicionais de localização industrial, a exemplo de um mercado consumidor dinâmico ou um sistema de transportes estruturado.

Tais observações destoam das afirmativas segundo as quais há uma redução da participação do Estado nos componentes de produção socioespaciais. Ao analisar o papel do Estado na sociedade, conforme percebemos, ele representa, sobretudo, um conteúdo e uma forma dos processos sociais e, como tal, não só se coloca como mediador de conflitos sociais, mas também como instrumento de uma classe. Portanto, fica difícil falar de desintegração do Estado, sendo mais lúcido retomar a discussão sobre seu papel na organização da sociedade atual.

Essa reflexão nos parece pertinente para interpretar o recente desenvolvimento da atividade industrial no Ceará nas duas últimas décadas. O processo de industrialização aí consolidado está intimamente ligado à participação efetiva do Estado, diretamente responsável não só pela reestruturação dos padrões econômicos, mas também pela atração de inúmeros investimentos, sobretudo os procedentes do Sul e Sudeste do país.

As mudanças da base produtiva são o resultado de um projeto político-econômico responsável por facilitar a penetração dos mecanismos de produção/reprodução capitalista no território cearense. Tais transformações, que vinham acompanhadas no plano político por uma série de reformas, são confirmadas através do uso de ações emblemáticas de incentivo à industrialização.

Isso contribuiu decisivamente para que as relações de produção assumissem uma natureza mercantil, garantindo, conseqüentemente, que obstáculos resistentes do ponto de vista da esfera política pudessem ser suplantados a partir da racionalidade imposta pelas relações fundamentadas na forma-mercadoria. Neste caso, "é como se o chão, por meio das técnicas e das decisões políticas que incorpora, constituísse um verdadeiro depósito de fluxos de mais-valia, transferindo valor às firmas nele sediadas" (SANTOS, 2002, p. 88).

Já no final dos anos de 1970 a economia cearense assiste à passagem de um sistema produtivo agrário-exportador para outro centralizado na indústria e no comércio e serviços. O que se observa a partir de então é a superação do tradicional ordenamento econômico, no qual a antiga proeminência da atividade agropecuária abre espaço para uma economia moderna e dominada pelas relações eminentemente capitalistas.

Mas os elementos que consolidam a economia de mercado no Ceará, são definitivamente incorporados com as mudanças políticas desencadeadas na década de 1980, quando um grupo de "jovens empresários", autônomos do poder local, se propõe a reestruturar as relações sócio-econômicas no Estado. Tal projeto consistiu primeiramente na retirada dos investimentos diretos do Governo, deixando a ele apenas o papel de propulsor do crescimento econômico. Num outro momento foi necessária uma recuperação das finanças públicas a partir de uma flexibilização da ação governamental no tratamento das demandas sociais. Desde então, esse modelo vem sendo reproduzido até os anos atuais, garantindo a efetivação de uma prática neodesenvolvimentista (ABU-EL-HAJ, 1997), fortemente calcada numa filosofia burguesa, empenhada no fortalecimento de tendências industrializantes, na ampliação da infra-estrutura produtiva e de circulação, na reestruturação da máquina do Estado baseada numa política de "privatização" e na atração de investimentos externos.

Os novos caminhos tomados pela organização política no Ceará tiveram papel fundamental na promoção/intensificação do processo de industrialização, evidenciados a partir de uma ação político- 
econômica intensa na qual a intervenção do Governo Estadual se dá através de uma parceria com o capital privado. O papel do Governo se coloca de maneira bem definida: fomentar a abertura do território para assegurar a chegada/consolidação do capital produtivo.

Mas como esse modelo de desenvolvimento industrial vem atingindo uma das regiões de maior expressão econômica do Ceará, a região do Baixo Jaguaribe, na fronteira com o Rio Grande do Norte? Como pensar a proeminência do ramo mais destacado na política de atração industrial, isto é, o calçadista e o papel de ramos mais antigos, geralmente desenvolvidos a partir de capitais locais? Apresentar algumas idéias acerca desses temas é o objetivo desse texto. Além deste item, o artigo trará uma discussão sobre as características dos arranjos produtivos locais da indústria regional, não esquecendo de relacionar o impacto que os mesmos exercem sobre a economia jaguaribana. Da mesma forma, será enfatizado o papel da nova indústria de calçados como componente importante da política de dinamização industrial. Finalmente, a relação entre o velho e o novo no processo produtivo da indústria conduzirá o debate às suas considerações finais.

\section{A REGIÃO DO BAIXO JAGUARIBE NO CONTEXTO: ARRANJOS PRODUTIVOS LOCAIS E TRANSFORMAÇÕES ECONÔMICAS}

A indústria de transformação teve importância menor para a dinamização inicial da economia urbana na região do Baixo Jaguaribe (ver figura 1). Isso ocorreu, entre outros, em função da proeminência de atividades como o comércio e os serviços na primeira metade do século XX, de forte influência para a organização espacial urbana e regional, sobretudo em função da comercialização do excedente extraído do campo, através da pecuária extensiva e do plantio do algodão (FERREIRA, 2003).

Com a intensificação da extração da cera da carnaúba nas várzeas do rio Jaguaribe e a valorização desse produto no mercado nacional e internacional a partir da década de 1960, os ritmos do comércio e dos serviços ganharam novo impulso, repercutindo sobremaneira na organização espacial urbana, no desenvolvimento das forças econômicas e na vida social da população local. Tal fato favoreceu a ascensão política de proprietários de carnaubais e comerciantes, implicando em maior acumulação do excedente agro-comercial e em interações espaciais mais abrangentes entre a região e outras parcelas do território (SOARES, 1999; CHAVES, 2004).

Como aponta Soares (2002), até meados da década de 1970 as atividades econômicas a se destacarem no Baixo Jaguaribe estiveram associadas à produção agrícola, à extração da cera da carnaúba e ao comércio e serviços. Como conseqüência, muito pouco do excedente extraído por tais atividades foi remanejado para a maquinofatura local, ficando a mesma marcada pela presença de pequenos estabelecimentos sem maior expressão econômica.

Nas décadas seguintes várias mudanças ocorreram. No que tange às atividades agrícolas, a região recebeu inúmeros investimentos, a maioria voltada para a modernização da produção agrícola e que primou pela aplicação técnica e científica no desenvolvimento da fruticultura, tendo como principal objetivo competir com o agronegócio globalizado. Tais transformações implicaram em expressivo impacto sócio-econômico, redefinindo os antigos padrões de organização espacial na região, como mostram os trabalhos de Elias (1999; 2002a; 2002b; 2005), entre outros.

As atividades industriais também apresentaram mudanças expressivas, sobretudo em suas organizações produtivas. Entre os ramos que mais se expandiram, merece referência o de confecção de redes de dormir (localizado em Jaguaruana), o metal-mecânico (desenvolvido em Tabuleiro do Norte) e o de produção de telhas (a dominar toda a região, e em especial o município de Russas). Todos esses investimentos foram responsáveis por um novo cenário na produção fabril e isso modificou o perfil produtivo e o mercado de trabalho na indústria, resultando na composição de arranjos produtivos locais - APLs marcados pela aglomeração espacial de empresas e o uso de estratégias político-econômicas singulares por agentes específicos regionais. 


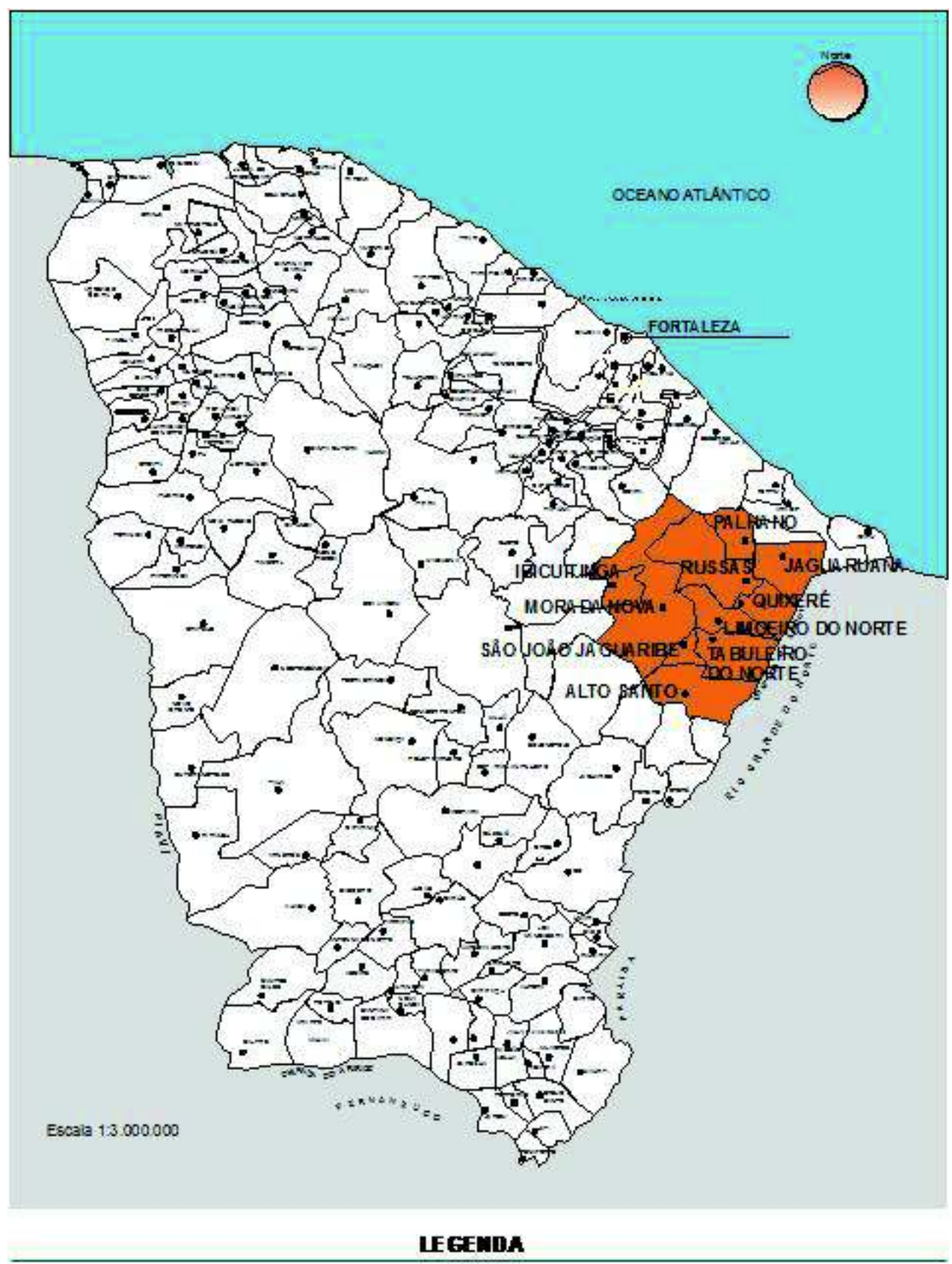

SEDES DUMCENS

PEGL̃̃o Do Baxo MgUAREE

Figura 1: A região do Baixo Jaguaribe no contexto do Estado do Ceará

Com a ação mais intensa dos programas do Governo do Estado na região, a partir da implantação de uma indústria de calçados do Grupo Dakota em Russas no ano de 1998, deu-se rápido processo de transformação da organização produtiva local, caracterizado pela dinamização da produção industrial. A indústria assumiu padrão competitivo, voltando seus produtos para o mercado nacional e internacional e sua produção consolidou um modelo fordista de desenvolvimento, estabelecendo relações de trabalho em que a esteira passou a controlar o processo produtivo, resultando em redefinição nos próprios ritmos de organização da vida quotidiana.

Mas apesar das transformações mais contundentes ter-se dado com a chegada da indústria de calçados, os outros ramos da produção industrial continuaram contribuindo com a expansão produtiva, mesmo que em parte deles eventuais crises gerassem perdas de rentabilidade. 
A análise de alguns indicadores aponta para relevante expressão dos arranjos produtivos locais na região, com efeito positivo sobre os empregos formais, a arrecadação de impostos e o consumo de energia na indústria.

A evolução das taxas para esta última variável, por exemplo, evidencia o processo recente de expansão. Segundo a tabela 1, entre os anos de 1988 e 2007, o consumo de energia industrial na região cresceu em $625 \%$, subindo de uma margem de 9.025 para $56.428 \mathrm{MWh}$. Se retirarmos os dados para o município de Russas, excluindo, portanto, os números da empresa Dakota Nordeste S/A e fornecedoras, a evolução não só representou índice contundente, como assumiu valores ainda mais expressivos, chegando a $656 \%$. Os municípios a contribuírem com esse avanço foram Jaguaruana, Limoeiro do Norte, Morada Nova e Alto Santo, a expandirem o consumo de energia entre 1988 e 2007 em 723\%, isto é, um aumento de mais de 32 mil MWh no total anual do consumo.

Tabela 1 - Consumo de energia industrial (MWh), segundo municípios da região do Baixo Jaguaribe - 1988/2007

\begin{tabular}{l|c|c|c|c}
\hline \multirow{2}{*}{ Municípios } & $\mathbf{4}$ Consumo de Energia Industrial (MWh) \\
\cline { 2 - 5 } Alto Santo & $\mathbf{1 9 8 8}$ & $\mathbf{1 9 9 3}$ & $\mathbf{2 0 0 0}$ & $\mathbf{2 0 0 7}$ \\
\hline Jbicuitinga & 420 & 743 & 3.896 & 1.230 \\
\hline Jaguaruana & $*$ & 18 & 25 & 23 \\
\hline Limoeiro do Norte & 1.218 & 3.257 & 9.349 & 17.454 \\
\hline Morada Nova & 2.883 & 5.314 & 8.832 & 11.425 \\
\hline Palhano & 642 & 1.448 & 4.676 & 7.221 \\
\hline Quixeré & 189 & 234 & 299 & 220 \\
\hline Russas & 195 & 276 & 606 & 801 \\
\hline São João do Jaguaribe & 3.095 & 4.046 & 10.992 & 17.489 \\
\hline Tabuleiro do Norte & 22 & 34 & 120 & 118 \\
\hline Baixo Jaguaribe & 361 & 409 & 405 & 447 \\
\hline
\end{tabular}

Fonte: Instituto de Pesquisa e Estratégia Econômica do Ceará - IPECE.

O desempenho das taxas de crescimento do Imposto sobre Produto Industrializado - IPI é outro fenômeno que vem confirmar a importância que os arranjos produtivos locais têm apresentado nesses últimos anos. Ele revela evolução para todo o Baixo Jaguaribe e demonstra avanço exponencial para alguns municípios que incorporaram novos investimentos entre os anos de 1997 e 2006 (tabela 2). Os números mostram a composição de dois grupos de municípios segundo a tendência de evolução das taxas. No primeiro caso, percebemos redução daquilo que é arrecado como tributo industrial nos municípios de Palhano e Ibicuitinga, confirmado pela menor expressividade industrial que estes municípios apresentam para a região.

Numa outra situação, estão os municípios que sofreram acréscimo impressionante no total arrecadado, entre os quais se destacam Tabuleiro do Norte (12.504\%), Limoeiro do Norte (5.201\%), Alto Santo (4.950\%), Russas (4.021\%), Jaguaruana (1.510\%), Morada Nova (1.500\%), Quixeré (930\%) e São João do Jaguaribe (535\%). Para este grupo, um fenômeno importante deve ser mencionado: os municípios a sofrerem os maiores incrementos são exatamente aqueles que concentram os APLs supracitados, em especial os arranjos metal-mecânico, ceramista e de confecções de redes de dormir. Acabam confirmando a relevância que os APLs apresentam para a arrecadação de IPI regional, assim como, revela o maior grau de formalização sofrido pelos ramos industriais mais antigos nos últimos anos.

Ao observar que a absorção da força de trabalho é um dos aspectos fundamentais do processo de desenvolvimento da atividade industrial, condicionando tanto o processo produtivo como as formas de consumo nas principais cidades, também consideramos os valores apresentados pelo estoque de empregos formais na indústria, fornecidos pelo Ministério do Trabalho e Emprego - MTE (tabela 
3). Com base nesta variável, não há redução no número total de vagas para nenhum município em análise entre 1985 e 2007, o que confirma forte tendência à racionalização das formas de trabalho no Baixo Jaguaribe, mesmo em ramos tradicionalmente conhecidos pela predominância da informalidade, como a indústria ceramista e de confecção de redes. A maior quantidade para o ano 2007 é representada por municípios como Russas (4.951), Jaguaruana (962), Limoeiro do Norte (889), Morada Nova (434) e Tabuleiro do Norte (340). Os outros municípios têm quantidade reduzida de empregos no mercado formal e isto está associado à pequena expressão econômica que a indústria local apresenta, dificultando a introdução de formas mais racionalizadas de trabalho para o processo produtivo no setor industrial.

Tabela 2 - Arrecadação de imposto sobre produto industrializado - IPI (R\$), segundo municípios da região do Baixo Jaguaribe - 1997/2006

\begin{tabular}{l|c|c|c}
\hline \multirow{2}{*}{ Municípios } & \multicolumn{3}{c}{ IPI (RS) } \\
\cline { 2 - 4 } & $\mathbf{1 9 9 7}$ & $\mathbf{2 0 0 1}$ & $\mathbf{2 0 0 6}$ \\
\hline Alto Santo & 148 & 2.508 & 7.239 \\
\hline lbicuitinga & $*$ & 0 & 0 \\
\hline Jaguaruana & 7.360 & 196.062 & 111.096 \\
\hline Limoeiro do Norte & 1.252 & 4.583 & 65.864 \\
\hline Morada Nova & 326 & 216 & 4.840 \\
\hline Palhano & 266 & 426 & 0 \\
\hline Quixeré & 820 & 26.564 & 7.639 \\
\hline Russas & 12.564 & 334.014 & 506.087 \\
\hline São João do Jaguaribe & 210 & 187 & 1.124 \\
\hline Tabuleiro do Norte & 1.974 & 6.282 & 246.071 \\
\hline Baixo Jaguaribe & 24.920 & 568.334 & 949.960 \\
\hline
\end{tabular}

Fonte: Secretaria Regional da Receita Federal (SRRF).

A região como um todo também apresenta evolução das taxas para os períodos 1985/1995 (85,5\%) e 1995/2007 (630\%), sendo que neste último caso, os níveis de expansão se distribuem mais expressivamente por todos os municípios, demonstrando que as transformações desencadeadas pelos novos mecanismos de modernização econômica não se confirmam sem redefinir o estoque de empregos formais em todo o Baixo Jaguaribe.

Tabela 3 - Estoque de empregos formais existente em 31/12 no setor industrial, segundo municípios da região do Baixo Jaguaribe - 1985/2007

\begin{tabular}{l|c|c|c}
\hline \multirow{2}{*}{ Municípios } & \multicolumn{3}{|c}{ Estoque de empregos formais } \\
\cline { 2 - 4 } & 1985 & 1995 & $\mathbf{2 0 0 7}$ \\
\hline Alto Santo & 16 & 4 & 167 \\
\hline Ibicuitinga & $*$ & $*$ & 0 \\
\hline Jaguaruana & 186 & 289 & 962 \\
\hline Limoeiro do Norte & 238 & 324 & 889 \\
\hline Morada Nova & 31 & 171 & 434 \\
\hline Palhano & 3 & 30 & 31 \\
\hline Quixeré & 14 & 39 & 78 \\
\hline Russas & 157 & 290 & 4.951 \\
\hline Sao Joao do Jaguaribe & 2 & 19 & 20 \\
\hline Tabuleiro do Norte & 23 & 76 & 340 \\
\hline Baixo Jaguaribe & 670 & 1.242 & 7.862 \\
\hline
\end{tabular}

Fonte: MTE/RAIS 
A partir dos indicadores observados e considerando as inúmeras informações extraídas a partir de entrevistas a empresários e trabalhadores locais, examinemos mais de perto o desempenho dos três principais arranjos produtivos locais da região.

\section{O Arranjo Ceramista}

A atividade ceramista no Nordeste se desenvolveu a partir da década de 1950, e desde então, tem-se organizado sobre duas direções distintas, a se saber: 1) a produção organizada a partir de uma base industrial, com maior produtividade e utilização de tecnologias semi-automáticas, e 2) o modelo mais tradicional, que conserva características bem rudimentares, abastecendo um mercado de abrangência exclusivamente local.

No Ceará, deu-se, sobretudo, a expansão deste segundo modelo, localizado nas margens dos principais rios, em função do aproveitamento da matéria-prima extraída nas planícies aluviais, sem a qual a produção se tornaria inviável. Nos últimos quarenta anos, os investimentos no ramo ganharam impulso com a gradativa substituição das habitações construídas à base de argila por casas mais estruturadas, a gerar grande demanda por produtos mais acabados como tijolos, telhas, lajotas, entre outros. O dinamismo sentido pela construção civil nas principais cidades cearenses, a exemplo de Fortaleza, também teve papel fundamental no aumento do consumo desses produtos, exigindo maior produtividade e o aperfeiçoamento da tecnologia utilizada pelo processo produtivo. Desde então, as tecnologias semi-automáticas foram instaladas nas cerâmicas.

Gradativamente, as empresas do Ceará ampliaram seu mercado para toda região Nordeste e alguns Estados como Bahia e Pernambuco, dois grandes consumidores em escala regional, passaram a ser abastecidos pelas cerâmicas cearenses. Isso fez dinamizar todo o ramo no Estado, fazendo com que nos últimos anos a produção fosse suficiente para abastecer o mercado interno e grande parte da demanda dos Estados nordestinos. Atualmente são, em média, 500 empresas, com diversas dimensões e responsáveis pelo abastecimento de grandes centros de consumo, como Salvador, Recife, Fortaleza, João Pessoa, entre outros.

No Baixo Jaguaribe, a produção ceramista tem contribuído desde muitas décadas com o crescimento econômico regional, ao lado de outras atividades importantes, como as lavouras frutícolas e a extração de cera de carnaúba. O seu desenvolvimento, entretanto, ocorreu no início dos anos de 1980, com a transformação sentida pela construção civil na região (casas de taipa sendo substituídas pelas de alvenaria) e a maior demanda por material de construção nas principais cidades do Estado, em conseqüência, sobretudo, das políticas habitacionais implementadas pelo Governo Federal.

Diante desse contexto, multiplicou-se a produtividade na região, com destaque para os municípios localizados as margens dos rios Jaguaribe, Banabuiu e Quixeré, que concentraram mais estabelecimentos e passaram a abastecer a crescente demanda local, assim como a dos Estados vizinhos.

No princípio, houve a intenção de se produzir tijolos, telhas e lajotas para atender o consumo em nível estadual, mas o cumprimento dessa meta acabou se revelando inviável, especialmente porque a concorrência e o preço do frete não permitiam rentabilidade para o tijolo e a lajota. Os produtores locais, então, investiram exclusivamente na produção de telhas e o resultado foi a consolidação de um arranjo produtivo local importante, responsável por dinamização da economia, com conseqüências positivas para o mercado de trabalho e o comércio nas cidades.

A fase mais promissora se deu durante a década de 1980, com o aquecimento do mercado de materiais de construção proporcionado pelas políticas habitacionais do Governo do Presidente José Sarney. Em princípios dos anos de 1990, a quantidade de estabelecimentos na região aumentou, mas algumas medidas tomadas pelo Governo do Presidente Fernando Collor de Melo, de natureza mais neoliberal, acarretaram retração do consumo, a repercutir na rentabilidade dos produtores locais, acirrando a concorrência entre os ceramistas.

Mesmo assim, a quantidade de estabelecimentos de minerais não metálicos no Baixo Jaguaribe, que inclui principalmente as fábricas de cerâmica, avançou gradativamente de 1990 a 2007 
(IPECE, 2008). Isso é justificado por conta do grande número de empresas de menor porte que se instalou na região a partir da dinamização da produção e do consumo no final da década de 1980. Segundo alguns produtores mais antigos, esse fenômeno contribuiu para acentuar a crise no ramo, pois com o aumento da concorrência e a pequena inter-relação entre os produtores, o mercado se tornou uma arena de conflitos, na qual o preço do produto passou a ser negociado com base nos interesses individuais de cada empresário.

Os municípios que concentram o maior número de estabelecimentos em 2007 são Russas (80), Limoeiro do Norte (23) e Alto Santo (12), com taxas de crescimento que assumem valores consideráveis desde 1990. Mas é o município de Russas o responsável por apresentar a maior tradição na produção ceramista regional, não só por reunir a maioria das cerâmicas (o equivalente a $57 \%$ da região), mas também por ter introduzido a atividade no Baixo Jaguaribe.

Os primeiros estabelecimentos surgiram das antigas olarias localizadas às margens do rio Jaguaribe e do riacho Arahibu (no entorno da cidade de Russas), mas também na localidade de Ingá. Aos poucos ganharam expressão, escoando a produção para Fortaleza e outros Estados do Nordeste, com destaque para a Bahia. A boa margem de rentabilidade de algumas empresas, fez expandir a atividade para outras áreas, a exemplo do distrito russano de Flores, que atualmente concentra dezoito estabelecimentos, e de algumas localidades próximas às sedes de Limoeiro do Norte e Alto Santo.

A proximidade dos rios se faz essencial para as cerâmicas, pois entre as matérias-primas necessárias para a produção de telhas, a argila se apresenta como a de maior custo. Na verdade, esse é o principal motivo que impediu outras áreas no Nordeste a desenvolverem uma produtividade de destaque face à região. No Baixo Jaguaribe e, em especial, no município de Russas, as condições do solo aluvial são as mais apropriadas, o que implica diminuição dos custos de produção.

Em termos gerais, o arranjo produtivo ceramista do Baixo Jaguaribe, diminui sobremaneira as suas margens de rentabilidade nos últimos anos, o que acarreta falência ou paralisação temporária de muitos estabelecimentos. Entretanto, apesar do pequeno poder empreendedor dos empresários locais, da desqualificação dos funcionários e da baixa tecnologia utilizada na produção, o arranjo tende a preservar as maiores cerâmicas, em virtude, principalmente, da penetração de seus produtos nos mercados mais exigentes do Nordeste.

\section{A Produção de Redes de Dormir}

A origem da produção de redes de dormir no Baixo Jaguaribe é herança da cultura indígena na região. O processo de confecção sempre foi uma tarefa exclusiva das mulheres, que dominavam o saber técnico e o transmitiam para seus filhos como tradição familiar, reservando aos homens apenas as tarefas complementares. Com a expansão da produção têxtil, o homem passou a dominar todo o processo produtivo, transformando a fabricação simples e artesanal numa atividade comercial, voltada para o mercado local.

O município de Jaguaruana centralizou todo esse processo de desenvolvimento, reunindo por muitas décadas uma produção obtida a partir do trabalho realizado em pequenas unidades familiares, geralmente residencial, marcado pela utilização de instrumentos rudimentares como o "tear de três panos". Na década de 1950, com a utilização do "tear grande" ou "batelão", instrumento de tecer de madeira responsável pela "tapação" do tecido, a produção ganhou caráter definitivamente comercial e assumiu ares de uma atividade manufatureira de importância fundamental para o município, sendo comandada principalmente por artesãos locais.

A produção de redes de dormir a partir do "batelão" marcou importante mudança no processo produtivo como um todo. As atividades nesse instrumento requerem maior esforço físico, pois exigem do artesão a movimentação cadenciada de mãos, braços, pernas e cabeça, num ritmo em que são proibidos gestos bruscos. A maior capacidade produtiva do "batelão", capaz de confeccionar até vinte redes por dia, deu aos produtores expansiva penetração no mercado regional, garantindo ao município de Jaguaruana uma especialização no ramo têxtil e de confecções. 
Ao ampliar sua produção, Jaguaruana passou a atender a demanda de Fortaleza e de outros Estados do Nordeste e do Norte do país, a exemplo de Rio Grande do Norte, Piauí, Maranhão, Pará e Amazonas. Tal fato esteve associado diretamente à chegada do "tear elétrico", em 1980, que redefiniu o processo produtivo local, substituindo a técnica artesanal de alguns tecelões por um sistema moderno, caracterizado pela produção em escala num ritmo ampliado, agora realizado na fábrica.

$\mathrm{O}$ "tear elétrico" inseriu um modelo produtivo empresarial em Jaguaruana, no qual a antiga atividade artesanal têxtil foi substituída pelo trabalho racionalizado, preso a jornadas mais longas em galpões distribuídos pela sede do município. Os proprietários das fábricas ampliaram seu controle sobre os trabalhadores locais, impondo-lhes disciplina mais efetiva sobre o tempo de trabalho e a produtividade. O padrão industrial incorporou o saber técnico dos antigos artesões e gradativamente estes foram se proletarizando, mesmo que não tenham perdido a habilidade necessária para fazer do produto municipal um dos mais valorizados do mercado regional.

No começo da década de 1980, Jaguaruana já se apresentava como um dos maiores centros de produção de redes de dormir do Brasil, atraindo investimentos de outras áreas do Nordeste, interessados na abundante força de trabalho especializada. A dinamização do setor, marcada principalmente pela presença de empresas pequenas e médias, garantiu uma produção que abastecia também o mercado internacional, alcançando países como Portugal, Austrália e Alemanha, cada vez mais exigentes com a qualidade do produto.

Criou-se então o ambiente propício para a formação de um arranjo produtivo local de relativa importância, com participação de investidores locais e externos, comercializando a produção para o mercado nacional e internacional. Em meados da década de 1980, o período de maior destaque da produção e do consumo, a quantidade de redes produzidas por mês chegou a mais de 150.000 unidades, compreendendo um esquema de produção que envolvia desde bordadeiras, artesões, costureiras e operários das fábricas têxteis.

O processo de confecção e acabamento do produto se tornou mais complexo, perfazendo ao todo vinte e uma etapas, realizadas por trabalhadores responsáveis por diferentes funções, alguns contratados para o trabalho assalariado na fábrica, e outros subcontratados para prestarem serviços variados, que iam da costura ao bordado. No caso do trabalho informal, que correspondia à maioria dos postos oferecidos, a participação das mulheres era muito expressiva, com os serviços sendo realizados nas próprias residências das contratadas, sempre com remuneração inferior. É por isso que uma rápida visita ao distrito-sede de Jaguaruana, tanto nas décadas de 1980 e 1990, como ainda hoje, implica numa visão inusitada das calçadas da cidade, em grande parte tomadas por fios, redes e bordados diversos.

O desenvolvimento da produção também trouxe para o município três grandes fábricas têxteis, especializadas somente na produção de fios. Tratam-se da Jaguatêxtil S/A, da Multicor S/A e da Usina Santana S/A, que fabricam fios têxteis de qualidades diversas e negociam sua produção para diversos Estados do Brasil, em especial a Paraíba, o Mato Grosso, a Bahia, Goiás e Minas Gerais.

Na segunda metade da década de 1990 a produção de redes entra em processo de crise, determinada entre outros fatores, por baixa rentabilidade associada ao aumento da concorrência, ao despreparo financeiro e administrativo dos empresários e à incapacidade de reação dos produtores às oscilações do mercado nacional. Ocorre grande seqüência de falências das pequenas e médias empresas locais e a produção de outras regiões, como as de São Bento e de Cajazeiras na Paraíba, penetra fortemente nos mercados consumidores mais importantes de Jaguaruana, em especial o Norte do país.

Das 300 empresas que fabricavam redes em 1985, restam apenas 100, sendo que a maioria é formada por pequenos produtores que trabalham no fundo do quintal ou nos cômodos da casa, portanto, sem uma maior qualificação técnica ou industrial. No auge da produção, além da constante presença de compradores vindo de várias cidades do Ceará e do Nordeste, em média duas carretas partiam do município somente para abastecer o Estado do Pará, não sendo inferior a quantidade

Mercator - volume 9, número 18, 2010: jan./abr. 
comercializada com o Estado do Amazonas. Atualmente, a maioria das empresas a resistir à crise, negocia sua produção com Fortaleza e cidades próximas ou se submete aos interesses de atravessadores, situação a causar freqüente endividamento.

A exceção fica por conta de doze empresas médias que ainda possuem autonomia frente aos atravessadores e conseguem negociar com outros produtores têxteis da Região Metropolitana de Fortaleza, em especial Maracanaú, repassando a peça inteira ou inacabada para ser retrabalhada e revendida no mercado internacional. Algumas poucas fábricas dispõem de clientes próprios em países como Alemanha, Portugal e Suécia e vendem diretamente para tais mercados. Quando isso acontece, o produto é transportado através de navios a partir dos portos do Pecém e do Mucuripe, localizados na Região Metropolitana de Fortaleza.

Nos últimos anos, algumas políticas públicas de apoio à produção local procuram garantir a sobrevivência das empresas que resistiram ao período mais intenso da crise, em especial a proposta do Governo do Estado do Ceará de injetar benefícios fiscais e tributários no arranjo produtivo têxtil. O financiamento para a manutenção e aquisição de infra-estrutura, também abre maiores possibilidades de aperfeiçoamento tecnológico para alguns produtores, os quais, de certo modo, renovam ou ampliam seus equipamentos.

A partir do desempenho de algumas empresas, o arranjo sofre modesta recuperação, com alguns produtores ensaiando uma reestruturação gerencial e produtiva, marcada pela presença de formas mais flexíveis de produção e comercialização. Entretanto, essa maior dinamização está longe de causar os impactos sócio-econômicos do passado em Jaguaruana, sobretudo pelo pequeno apoio financeiro recebido pelos produtores locais e em razão da economia municipal já ter desenvolvido outras atividades de grande expressão econômica, como a fruticultura irrigada e a carcinicultura.

\section{O Arranjo Metal-Mecânico}

O complexo metal-mecânico no Ceará não é marcado por grande tradição, haja vista o Estado nunca ter desenvolvido técnicas relacionadas com a produção, processamento e utilização de metais. Mesmo assim, a fabricação de produtos metalúrgicos foi uma atividade comum nas principais cidades onde a demanda por equipamentos e máquinas mais simples era expressiva, sendo a construção civil o maior consumidor dos produtos fabricados em metalúrgicas e siderúrgicas de pequeno porte.

A despeito da pequena tradição, algumas empresas importantes, concentradas principalmente em Fortaleza e na Região Metropolitana, assumiram maior relevância, mesmo sem contribuir para a integração da cadeia produtiva metal-mecânica, sobretudo em virtude da diversidade e heterogeneidade da produção. Acabaram representando nichos específicos no ramo, a exemplo das empresas Esmaltec (botijões de gás e eletrodomésticos), Troller (veículos especiais), Metaneide (tambores de freios) e CEMEC (transformadores), que ampliaram o raio de ação para diversos Estados do Nordeste, Sudeste e Sul do país.

Diante da pequena articulação do complexo metal-mecânico estadual, restava ao ramo o desenvolvimento de iniciativas localizadas, criadas a partir de demandas bem particulares, específicas de cada região e geralmente estruturadas a partir de um modesto quadro tecnológico e operacional. Foi nesse contexto que se desenvolveu o arranjo produtivo metal-mecânico da região do Baixo Jaguaribe, localizado no município de Tabuleiro do Norte e organizado de tal forma a atender principalmente os interesses dos serviços mecânicos voltados para veículos de carga, bastantes difundidos pelo distrito-sede.

O município se tornou importante como centro metal-mecânico da região exatamente por reunir oficinas que criam, concertam e adaptam peças e equipamentos para caminhões e carretas. A atividade se aperfeiçoou e as antigas oficinas se tornaram montadoras, destacando a produção de veículos especiais e a formação de força de trabalho qualificada para serviços mecânicos. Com isso, Tabuleiro do Norte concentrou importantes oficinas, dos mais variados portes, atendendo às demandas regionais e aos veículos de carga que trafegavam pela BR-116, nas margens da cidade. 
Na primeira metade da década de 1980, as principais oficinas prosperaram e assumiram padrão capitalista, resultando no surgimento de fábricas, responsáveis pela produção de peças para veículos de carga, manutenção e conserto de máquinas e equipamentos. A empresa Tabuleiro Aço pode ser tomada como exemplo, na medida em que se tornou a maior empresa produtora de molas para caminhões do Ceará e assumiu importante segmento do mercado consumidor em Estados das regiões Norte e Nordeste do Brasil. Atualmente, produz em média 150 toneladas de molas ao mês e concentra 125 funcionários, com cerca de 110 na linha de produção.

Além desta empresa, existem 30 pequenas fábricas e oficinas com cerca de dez funcionários cada, movimentando um circuito de produção, venda e consumo associada à mecânica em geral, que atende todas as demandas da região do Baixo Jaguaribe e de outros municípios do Estado. Fabricam diversos produtos, entre os quais poderiam ser citados: ferragens para transformadores, peças para veículos, máquinas e equipamentos para cerâmica vermelha, ferramentas de uso na atividade agrícola, bombas de sucção, tubos e outros materiais produzidos sob encomenda.

Mas mesmo se apresentando como um arranjo produtivo local que reúne relativo número de funcionários, a maioria dos postos que se abre é para o mercado não formal. Isso se dá em razão das metalúrgicas se sustentarem a partir do trabalho familiar, onde pais, filhos e outros parentes dividem os serviços na linha de produção. Por tal razão, a força de trabalho não tem especialização técnica, e o apego à tradição faz com que grande parte dos funcionários resista a qualquer tipo de treinamento oferecido por instituições como o SEBRAE, o SENAI ou outras de qualificação operacional. Isso não impede que desenvolvam produtos modernos, que no ato da fabricação exijam preparação cuidadosa e complexa. Entretanto, no caso da maioria dos mecânicos, a habilidade se deu única e exclusivamente por conta dos muitos anos de experiência na atividade.

Muito recentemente, uma parceria estabelecida com os centros de formação técnica do município de Limoeiro do Norte oferece cursos de qualificação tecnológica para os filhos dos proprietários das oficinas. Isso permite abrir novas possibilidades de aperfeiçoamento dos serviços e expandir o mercado consumidor das empresas locais. No entanto, a especialização profissional ainda se apresenta reduzida, principalmente no que diz respeito à aplicação de algumas tecnologias e aos procedimentos do trabalho técnico na própria fábrica.

Nesse sentido, apesar do avanço revelado pelo arranjo metal-mecânico em Tabuleiro do Norte e do maior aperfeiçoamento do trabalho nas unidades de produção, as empresas locais ainda apresentam feição bastante modesta, sem possuir sequer estrutura apropriada para o desenvolvimento das atividades. Isso fica evidente quando observamos muitas oficinas desestruturadas, sem fachadas ou qualquer apresentação comercial. Distribuídas pelas ruas do centro da cidade, mesmo assim expressam maior tendência de dinamização da produção industrial local, prometendo melhores perspectivas para a organização econômica do município.

\section{INSERÇÃO DO PADRÃO FORDISTA DE PRODUÇÃO INDUSTRIAL: REGIÃO DO BAIXO JAGUARIBE NO CIRCUITO PRODUTIVO CALÇADISTA CEARENSE}

Apesar do importante aspecto apresentado pelos arranjos produtivos locais da indústria na região do Baixo Jaguaribe, estes destacam empresas que não modernizaram a lógica da produção industrial, concentrando inversões de pouca inserção nos mercados nacional e internacional. Compõe conjunto de estabelecimentos que, em sua maioria, faz parte de um circuito inferior da economia (SANTOS, 1979), desenvolvidos a partir de iniciativas locais com pequena ou nenhuma margem de investimentos externos e favorecidos pelas condições específicas regionais, aproveitando a oferta diferenciada de matéria-prima, transporte ou força de trabalho.

As mudanças mais radicais no quadro industrial da região se consolidam a partir da instalação de investimentos patrocinados pelo Governo do Estado na década de 1990, que trouxe principalmente para o município de Russas, uma das maiores empresas de calçados do Brasil, a Dakota S/A, 
responsável por inserir novo ritmo de racionalização nas relações de trabalho e criar uma cadeia de produção que chega a gerar efeitos positivos na atração de outros investimentos para o ramo.

Com a chegada da Dakota, a região se inseriu numa nova lógica da produção capitalista em que a produção está voltada para abastecer o mercado nacional e internacional com produtos fabricados na periferia dos maiores centros industrializados. É o resultado de estratégias político-econômicas interessadas em integrar o Ceará numa nova economia de trocas nacionais e globais. Desse modo, o objetivo do Estado de se impor solidamente na conquista de investimentos industriais externos foi atendido quando grupos empresariais já consolidados nacionalmente, sobretudo nos ramos têxtil e de calçados, optaram por abrir grandes fábricas no seu território.

Além de inúmeros subsídios, criados por Lei e regulamentados por Decretos-Lei, destacou-se na atração desses novos empreendimentos os custos com a força de trabalho e a pequena tradição do movimento operário local, situação que permitiu maior inserção de modelos flexíveis e precarizados de trabalho na fábrica.

No caso específico do ramo calçadista, tradicionalmente conhecido por recrutar grande força de trabalho, essas vantagens ganharam ainda mais relevância, confirmada pela penetração de estabelecimentos por todo o interior do Ceará, com destaque para as fábricas instaladas pelos grupos Dakota, Grendene e Vulcabrás nos municípios de Russas, Iguatu, Sobral, Crato, Horizonte, entre outros.

O Ceará aparece, então, como um atrativo para as grandes empresas justamente por contar com as condições favoráveis ao desenvolvimento da atividade, onde os mecanismos fiscais e os programas de desenvolvimento industrial, somados à força de trabalho a baixo custo, despontam como os principais impulsionadores da chegada de novos investimentos ligados à indústria.

\section{Os Reflexos sobre o Município de Russas na Região do Baixo Jaguaribe}

O município de Russas revela as transformações impostas pela atividade industrial, se colocando como importante exemplo de lugar de reserva apreendido por forças que fogem ao controle do poder local e regional. A montagem de uma fábrica do Grupo Dakota S/A, de origem gaúcha, causou à população local grande impacto, representado tanto pela maior participação da indústria na vida social, quanto pelo dinamismo sentido na economia urbana e nas relações de trabalho.

Marcado por forte expressão urbano regional, Russas sempre se destacou na região do Baixo Jaguaribe pela centralidade política e econômica que exerceu frente aos demais municípios. Sua sede, juntamente com as dos municípios de Limoeiro do Norte e Morada Nova, se apresenta como centro de um conjunto de cidades que nasceram numa área caracterizada pela fertilidade do solo aluvial e pela abundância d'água, muito úteis para o desenvolvimento de atividades como a agricultura de subsistência, a pecuária extensiva e o extrativismo vegetal.

Como importante núcleo urbano de uma região estratégica no acesso ao sertão cearense, com componentes históricos, políticos e econômicos também de relevância para o Estado, a cidade se impôs pelas atividades econômicas ligadas aos ramos do comércio e dos serviços, responsáveis por intenso fluxo a materializar no centro comercial grande dinâmica de pessoas e objetos. Um conjunto de empresas, também responsáveis pela fabricação de produtos consumidos pela população local, se concentrava no município, garantindo o abastecimento de uma demanda regional de relativa expressão (PEREIRA JÚNIOR, 2005).

Em linhas gerais, entretanto, a economia urbana indicava estrutura tradicional, com os equipamentos e os serviços da cidade expressando quadro modesto. As relações de produção e uso das riquezas também apresentavam expressão somente regional, na medida em que a maior parte das empresas, especializadas principalmente na fabricação de cerâmicas e no aproveitamento da produção agrícola, era de pequeno porte, se traduzindo em empreendimentos locais com número reduzido de trabalhadores.

A partir de 1998 a Dakota Nordeste S/A e outras pequenas indústrias fornecedoras mudaram gradativamente esse quadro. Motivadas pelo dinamismo implementado, as relações de produção 
e trabalho assumiram maior complexidade, fato revelado pela emergência de novas formas de emprego, assim como, pela intensificação dos fluxos no comércio e nos serviços. A nova dinâmica empregou conjunto de mudanças que paulatinamente passou a redefinir a ordem anterior, reestruturando antigos referenciais de sociabilidade em nome da imposição de valores da sociedade de mercado. Conseqüentemente, a incorporação de uma dinâmica industrial completamente nova em Russas implicou transformação econômica a se materializar rapidamente no território, criando uma rede de fluxos responsáveis por novas noções de deslocamento, aproximação e funcionalidade.

Alguns indicadores ilustram o conjunto de transformações supracitado, dentre os quais merecem destaque, primeiramente, os números oferecidos pelo IPECE para o Produto Interno Bruto - PIB municipal entre os anos de 1997 (imediatamente anterior ao ano de chegada da maioria das empresas) e 2006. Se, no primeiro ano, Russas indicava um PIB de cerca de R $\$ 90$ milhões a preço de mercado, em 2006, esse número ultrapassa os R\$ 347 milhões, revelando acréscimo de $286 \%$. Este aumento, além de garantir ao município o maior PIB do Baixo Jaguaribe, supera também o aumento dos municípios que mais cresceram no período, a se saber, respectivamente, Limoeiro do Norte (276\%) e Morada Nova (141\%). Quando se leva em consideração o aumento do PIB per capta para o mesmo período, Russas também é um dos grandes destaques da região, passando de $\mathrm{R} \$ 1.691,00$ em 1997, para R\$ 5.320,00, em 2006.

Os números do emprego na indústria e no comércio e serviços também indicam crescimento, expressando o quanto toda dinâmica vem redefinindo as relações de trabalho no município. Se for analisada a expansão do estoque de empregos formais por grande grupo ocupacional do Ministério do Trabalho (MTE) entre os anos de 1990 e 2007, é possível perceber acréscimo impressionante no trabalho da indústria, com expansão em média de 4.648\%, passando de um contingente de 126 para 4.951 funcionários. Os índices do mercado de trabalho no comércio e nos serviços também aumentam, na medida em que aponta expansão do estoque de empregos formais de $244 \%$ no referido período, crescendo de 1.289 para 4.454 trabalhadores.

Tais números vão legitimar a força de um processo de reestruturação em Russas, responsável tanto pelo aguçamento dos choques sócio-econômicos, quanto pela materialização de um conflito erguido entre as práticas preexistentes e a nova dinâmica.

\section{A Dakota Nordeste}

O destaque na produção de calçados nacional é, sem sombra de dúvida, a região do Vale dos Sinos, situada no Estado do Rio Grande do Sul. Essa região concentra em torno de $60 \%$ da indústria de componentes e $80 \%$ da indústria brasileira de máquinas para couros e calçados, onde também encontramos as instituições de ensino técnico e os centros de pesquisa e assistência tecnológica, que atende ao gênero calçadista. A hegemonia gaúcha ocorreu principalmente a partir do início da década de 1980, período em que o ramo sofreu forte crescimento de produtividade e se inseriu no mercado internacional.

Contudo, no início da década de 1990, as empresas calçadistas gaúchas entraram em profundo processo de reestruturação produtiva e isso se deu por dois motivos em especial: 1) as mudanças tecnológicas e produtivas levaram às novas formas de organização mais flexíveis, tanto na produção como na subcontratação da força de trabalho, recorrendo a uma maior divisão territorial das etapas para a produção calçadista; 2) as margens de rentabilidade da indústria gaúcha caíram por conseqüência da maior concorrência internacional com empresas calçadistas de países asiáticos.

Como estratégia de redução de custos e fuga da crise, algumas empresas do Rio Grande do Sul migraram para outros Estados do Brasil na busca de novas condições de produção que favorecessem a ampliação do mercado consumidor, no intuito de enfrentar os desafios impostos pela mundialização da economia (PEREIRA JÚNIOR e GADELHA, 2006).

A empresa gaúcha Dakota S/A é um exemplo desse processo. Inicia a desconcentração das suas unidades no ano de 1995, chegando ao Estado do Ceará, inicialmente, no município de Ma- 
ranguape, e posteriormente nos municípios de Iguatu e Russas. A empresa é um dos destaques na indústria calçadista cearense, ocupando a segunda posição no ranking estadual de produção de pares de sapatos ao ano.

A Dakota Nordeste S/A chegou ao município de Russas em 1998 com a instalação da sede nordestina da empresa, que passaria a se configurar como a maior unidade cearense em produção e contratação de força de trabalho. Nos primeiros dois anos de funcionamento, reunia apenas 300 funcionários e se encontrava instalada num galpão alugado, só adquirindo sua atual estrutura no ano de 2000. Hoje, a empresa apresenta uma área coberta de 30.000 metros quadrados, dispondo de uma média de 3.000 funcionários, responsáveis por uma produção de mais de 8.000 mil pares de sapatos por dia. Sua localização pode ser considerada estratégica, primeiro, por estar nas margens da BR-116, principal via de escoamento da produção no Estado, e depois, por se situar numa posição intermediária entre as duas outras unidades da empresa, se apresentando também como a única fábrica a produzir solados para todas as outras unidades do Ceará.

Encontra-se, ainda, próxima ao Complexo Portuário do Pécem e ao aeroporto internacional Pinto Martins, localizados na Região Metropolitana de Fortaleza, lhe conferindo vantagens para aquisição de matérias-primas e exportação do produto final, já que o Ceará possui localização estratégica em relação ao mercado exterior, reduzindo os custos de exportação, principalmente para os Estados Unidos e a Europa.

Mas a Dakota ainda guarda fortes laços com o Rio Grande do Sul. É neste Estado onde se encontra a matriz nacional e, sobretudo, onde o processo produtivo se inicia, através do repasse das demandas e da elaboração do design do produto. Assim, a unidade de Russas não define sobre o que, quando ou como produzir, colocando-se como componente fundamental de uma divisão territorial do trabalho que rearranja a topologia da empresa. Trata-se de um exemplo das novas qualidades e das novas espessuras adquiridas pela porosidade do território, que, como afirma Arroyo (2001) ao estudar o circuito espacial do calçado, confirma a capacidade dos grandes grupos empresariais de impor seus interesses na busca por lugares mais rentáveis.

No que diz respeito à aquisição de matéria-prima, a articulação territorial é diversa, uma vez que os insumos necessários à produção são oriundos de quatro regiões brasileiras, a exceção da região Norte. O Sul, Sudeste e Centro-Oeste são responsáveis, respectivamente, por 35,2 e 15\% da origem de matéria-prima, com o couro beneficiado se apresentando como o principal insumo, sobretudo aquele produzido nos Estados do Rio Grande do Sul, Paraná, São Paulo, Mato Grosso e Goiás. Completa o circuito espacial fornecedor de matéria-prima para a unidade local, os produtos oriundos do Ceará ( $20 \%$ dos insumos) e de outros Estados nordestinos (10\% daquilo que é consumido).

Quanto à distribuição da produção, a empresa também se articula com diferentes lugares, entre os quais se destacam os contatos com as regiões Sudeste e Sul e aqueles estabelecidos com outros países, principalmente os Estado Unidos, o México e os países da América do Sul, a exemplo do Chile, Peru e Colômbia. É preciso mencionar que a Dakota em Russas se especializou na fabricação de dois tipos de produtos finais na sua linha de produção, a sola e o calçado, e o seu circuito espacial de distribuição se organiza em função exatamente da maior demanda por estes produtos.

No que diz respeito à produção de sola, o circuito espacial de distribuição é estadual, com a empresa fornecendo o produto para a fabricação de calçados nas outras duas unidades de produção cearense, localizadas em Maranguape e Iguatu. Quanto ao calçado pronto, o raio de abrangência da distribuição é bem mais amplo, atingindo tanto o Ceará e as regiões Sul, Sudeste e Centro-Oeste do Brasil, como os países anteriormente citados, que consomem cerca de $8 \%$ da produção total.

No Ceará, o consumo é reduzido, chegando apenas a cinco por cento do que é produzido pela empresa. Enquanto isso, as outras regiões ficam com os demais $87 \%$ da produção, com os Estados de São Paulo, Rio Grande do Sul e Minas Gerais, assumindo papel de destaque. Um fenômeno importante, conforme ele demonstra, revela que nenhum comerciante da cidade de Russas, a trabalhar com o gênero de calçados, estabelece relações com a empresa, sendo difícil até mesmo a 
obtenção de um modelo Dakota nas lojas da cidade. Isso confirma que os laços existentes entre o município e a empresa se dão principalmente a partir da conveniência desta última, pois, à exceção dos benefícios oferecidos pela oferta barata e abundante de força de trabalho, não há razão para uma maior articulação com o mercado local.

$\mathrm{Na}$ organização do processo produtivo, a indústria possui duas divisões instaladas em quatro grandes galpões diretamente articulados. A primeira delas é a Divisão de Solados, que trabalha na produção de solas para todos os tipos de calçados, produzindo uma média de cinqüenta mil pares de solas por dia. A Divisão de Solados se diferencia por ser a única que opera em três turnos: A, $\mathrm{B}$ e C, funcionando vinte e quatro horas por dia, para dar conta da produção que abastece todas as unidades da empresa no Nordeste. É nesta divisão que as solas injetadas são produzidas, marcando o inicio da montagem do calçado. Grandes máquinas automáticas dominam esta etapa da produção, onde os trabalhadores, principalmente homens, entram em contato com os mais variados produtos químicos estocados em um galpão ao lado, o almoxarifado da Divisão de Solados. É interessante ressaltar que o almoxarifado da Dakota Nordeste, em Russas, por ser a matriz regional, é responsável por receber toda a matéria-prima adquirida pelas unidades instaladas no Ceará, ocupando grande parte da planta da empresa.

Com o término da injeção da sola, base para a fabricação de calçados, o produto é enviado para o setor seguinte, passando por uma lavagem e pela primeira pintura, seguindo para uma esteira onde será feito o retoque. Nesta última função, o trabalho das mulheres compõe maioria. Finalizado o processo produtivo da sola, o produto é dividido de acordo com o tamanho e modelo, sendo distribuído para as três unidades da empresa, respeitando a demanda solicitada por cada uma delas. As solas que ficam na Dakota Nordeste, em Russas, seguem para a divisão de calçados, onde a peça será montada e costurada.

$\mathrm{Na}$ Divisão de Calçados, a esteira fordista ainda é predominante. Nessa unidade, a empresa é dividida em pequenas fábricas, que ficam responsáveis pela produção de um determinado tipo de calçado. A jornada de trabalho é de um único turno, das sete às 15 horas, chegando a concentrar mais de $50 \%$ do número de funcionários. Vale destacar que as mulheres compõem maioria nessa divisão, principalmente na parte do acabamento e costura, a exigir maior cuidado e detalhamento na produção.

Depois de produzido o calçado, o mesmo é separado de acordo com o tamanho e o modelo, seguindo para a seção de embalagem onde é colocado em caixas, marcando o fim do processo produtivo. Com isso, as caixas seguem para a seção de expedição, quando o produto final é distribuído pelos caminhões que aguardam no pátio da fábrica.

Apesar da estruturação produtiva fordista apresentada e mesmo realizando todas as etapas da produção calçadista na sua própria fábrica, a empresa também insere algumas estratégias da produção flexível, operando de acordo com o pedido dos clientes realizado junto à matriz no Rio Grande do Sul. Os pedidos chegam ao Departamento de Programação da unidade de Russas, que controla praticamente todo o ritmo da produção. Suas funções são: 1) receber e organizar a encomenda; 2) enviar informações acerca da quantidade e do tempo necessário para a produção; 3) controlar o ritmo da esteira, sobretudo para garantir o atendimento ao cliente na quantidade e no tempo exigido; e 4) realizar a expedição do produto.

A Dakota Nordeste trabalha com uma média 100 a 150 linhas de calçados, com 10 a 12 modelos diferentes, mudando a produção de acordo com as tendências da moda e as estações do ano, o que implica necessidade de flexibilização da produção e do trabalho operário.

Diferentemente dos estabelecimentos industriais mais antigos da região do Baixo Jaguaribe, a unidade de produção da Dakota apresenta grande dimensão, localizando-se na saída noroeste da sede municipal de Russas e impondo movimento diferenciado à cidade. O equipamento também marca os novos ritmos sentidos pelo espaço urbano, no qual um fluxo expressivo de funcionários, vendedores, mototaxistas, entre outros, dominam o cenário local. 
Um elemento revelador dessa territorialidade urbana é a frota de ônibus da empresa Viação Russana, que prontamente às 17 horas se perfila defronte à fábrica para garantir o transporte dos funcionários. Cada um dos ônibus está identificado com o número da sua rota, que indica o itinerário percorrido, atendendo a zona urbana, os distritos, as localidades e até outros municípios. No mesmo instante, os demais funcionários pedestres, ciclistas e motociclistas, disputam espaço nas calçadas, no "bicicletário" e no estacionamento da fábrica, acelerando o movimento da paisagem. Num breve momento, que deve durar aproximadamente 30 minutos, algumas pessoas, carros, motos e bicicletas "tomam de assalto" as avenidas próximas, indicando mobilidade de trabalhadores que saem da fábrica com a mesma pressa com que se dispersam pelas ruas da cidade.

Todo processo revela múltiplos rebatimentos da Dakota Nordeste sobre o município de Russas e sobre a região do Baixo Jaguaribe. É possível verificar a materialização de novos objetos e movimentos na economia da região, confirmando que o advento da indústria não se completa sem antes alterar o conteúdo social e econômico da sociedade como um todo, imprimindo-lhe diferentes aspectos. A organização do espaço urbano também não fica indiferente ao novo fixo: ganha mais fluidez e, da mesma forma como sente a velocidade das pessoas e dos produtos na cidade, consolida sua maior articulação. Temos, por fim, um conjunto de mudanças a atingir a vida social urbana e a organização da paisagem, um processo de reestruturação que só se completa quando materializa seus componentes no território.

\section{CONSIDERAÇÕES FINAIS}

A organização do processo produtivo industrial na região do Baixo Jaguaribe é marcada por duplo perfil, no qual é possível depararmos com a presença tanto de arranjos produtivos locais, entre os quais poderiam ser citados o ceramista e o de confecções de redes, como por investimentos de capital externo, atraídos a partir de uma série de benefícios, com destaque para os incentivos fiscais e a força de trabalho a baixo custo.

Os arranjos produtivos locais foram responsáveis por importante dinamismo econômico nas últimas três décadas, atingindo sobremaneira a economia, as relações de trabalho e todas as formas de organização que determinam os ritmos da vida social. Representam a montagem e a consolidação de atividades econômicas, que mesmo sem incentivo público ou qualquer contribuição dos investimentos externos, se impuseram no processo produtivo, garantindo certo grau de acumulação do excedente capaz de reproduzir a produção industrial e a força de trabalho, muitas vezes em ritmo expressivo. Correspondem a exemplos típicos de arranjos que resultam de combinações específicas de processos históricos regionais e locais, somados a estratégias e táticas singulares, levadas a efeito por agentes, instituições e organizações em territórios únicos (PIRES e VERDI, 2009).

Esses empreendimentos, porém, oscilam entre períodos de crise e expansão da produção, resultando em atividades econômicas bastante instáveis, marcadas por constante contratação e demissão de funcionários. Nos últimos anos, por exemplo, a maioria dos estabelecimentos amarga sérios problemas com a concorrência e o aumento dos custos com matéria-prima e energia, a despeito do início da década de 1980, quando a produção industrial não só se impunha, como conquistava amplas parcelas de um mercado consumidor cada vez mais abrangente.

Por outro lado, paralelamente a esse modelo, a região sofre maior impacto do setor industrial calçadista, como conseqüência da abertura econômica ao grande capital, assim como, pela inserção da atual lógica flexível que favorece a incorporação de novos lugares ao processo global de reprodução capitalista. Os avanços da técnica incorporada à produção industrial e o aprofundamento da divisão territorial do trabalho determinam novas relações no plano espacial e a região do Baixo Jaguaribe, mais especificamente o município de Russas, sofre diretamente o efeito dessas forças a partir da instalação de uma fábrica do setor de calçados da empresa Dakota S/A, de origem gaúcha. O fenômeno caminha na direção de viabilizar o processo de reprodução das relações capitalistas de 
produção, instalando no lugar um novo quadro de produção racionalizada, baseado na produção em massa e na organização do trabalho formal, subdivido numa linha fordista de produção.

Entre as principais mudanças advindas da instalação da Dakota Nordeste em Russas merece destaque o novo mercado de trabalho gerado pela indústria na região jaguaribana como um todo, além de transformações nos componentes responsáveis pelas formas de consumo e pela organização do espaço urbano, a consolidar importantes mudanças nas forças que movimentam os fluxos e os objetos no território. Com isso, os reflexos da nova lógica industrial não tardam a se materializar na organização socioespacial, com destaque para novos ritmos que revelam maior dinamismo na economia, cada vez mais marcada pela aceleração das transformações.

As mudanças devem ser analisadas tendo como pano de fundo a lógica que se desenha em escala mundial, no que diz respeito ao papel que os lugares representam para a expansão das margens de acumulação da economia global. Mesmo com a prioridade dada às atividades ligadas aos serviços e as finanças, o capitalismo tem como base de sustentação à contradição capital/trabalho, que com suas metamorfoses atuais continua desempenhando grande papel no processo de reprodução das riquezas.

As fragilidades impostas pela concorrência global e a necessidade de aumentar ainda mais os lucros leva o capital a passar por mutações no interior do processo de acumulação para que o dinamismo necessário ao aumento de seu giro seja garantido. Nesse contexto, o controle do trabalho aparece como estratégia fundamental para o desenvolvimento pleno do capitalismo. A escolha da região do Baixo Jaguaribe, mais especificamente o município de Russas como novo lócus da produção de calçados não é aleatória. $\mathrm{O}$ fator força de trabalho, como vimos, é de fundamental importância para o sucesso do investimento de empresas que ainda recrutam grande contingente de trabalhadores. A adaptação dos funcionários ao tempo da esteira fordista e da jornada de trabalho, que chega até nove horas de duração, traz grande impacto na vida da população, que acostumada ao tempo lento das pequenas cidades e ao trabalho no campo são inseridos na racionalidade capitalista.

Dessa forma, a organização do espaço industrial no Baixo Jaguaribe, abrange todos os componentes responsáveis pela reestruturação do território, reunindo os mais recentes valores evidenciados pela alteração de certos elementos, mas preservando alguns antigos padrões produtivos, resultando na concomitância de velhos e novos aspectos da atividade industrial.

Por fim, a região vai sentir os efeitos da própria condição de existência do desenvolvimento das forças industriais na modernidade, um ordenamento que remete à organização espacial um acúmulo crescente de objetos e velocidades, mas, em contrapartida, produz uma realidade marcada pelo abrangente crescimento das contradições.

\section{REFERÊNCIA BIBLIOGRÁFICA}

ABU-EL-HAJ, Jawdat. Neodesenvolvimentismo no Ceará: autonomia empresarial e política industrial. Revista Econômica do Nordeste. Fortaleza: BNB. v. 3, n. ${ }^{\circ}$ 28, pp. 327-345. 1997.

ARROYO, Mônica. Território nacional e mercado externo - uma leitura do Brasil na virada do século XX. Tese (Doutorado em Geografia). Universidade de São Paulo, São Paulo, 2001.

CAMAGNI, Roberto. Economia urbana. Barcelona: Antoni Bosch, 2005.

CHAVES, Maria Lucenir Jerônimo. Urbanização e modernização da agricultura em Limoeiro do Norte (CE): impactos socioespaciais. Dissertação (Mestrado em Geografia). Universidade Estadual do Ceará, Fortaleza, 2004.

ELIAS, Denise. A atividade agropecuária do Estado do Ceará no contexto da globalização. In: AMORA, Zenilde Baima. O Ceará: enfoques geográficos. Fortaleza: Editora FUNECE, 1999. pp. 25-42.

ELIAS, Denise. Modernização da produção agropecuária. In: Elias, Denise. O Novo espaço da produção globalizada - O Baixo Jaguaribe - CE. Fortaleza: Edições Demócrito Rocha, 2002a. pp. 281-355.

ELIAS, Denise. Integração competitiva do semi-árido. In: ELIAS, Denise. SAMPAIO, José Levi Furtado. Modernização excludente. Fortaleza: Edições Demócrito Rocha, 2002b. pp. 11-36. 
ELIAS, Denise. Territorialização do capital no espaço agrário cearense. Geografia, Rio Claro-SP: AGETEO, v. 30, n. ${ }^{\circ}$ 2, pp. 223-239, mai./ago. 2005.

FERREIRA, Cicinato Neto. Estudos de história jaguaribana: documentos, notas e ensaios diversos para a história do Baixo e Médio Jaguaribe. Fortaleza: Premius, 2003.

GOVERNO DO ESTADO DO CEARÁ. Plano plurianual - política industrial. Fortaleza, 1995.

INSTITUTO DE PESQUISA E ESTRATÉGIA ECONÔMICA DO CEARÁ - IPECE. Anuário estatístico do Ceará 2001. Tomo 2: economia e finanças. Fortaleza, 2001.

INSTITUTO DE PESQUISA E ESTRATÉGIA ECONÔMICA DO CEARÁ - IPECE. Anuário estatístico do Ceará 2008. Disponível em http://www.iplance.ce.gov.br. Acesso em 20 de abril de 2009.

KON, Anita. Economia industrial. São Paulo: Nobel, 1999.

LIMA, Luiz Cruz; ROCHA, Adriana Marques. Expansão do terciário. In: Elias, Denise. O Novo espaço da produção globalizada - O Baixo Jaguaribe -CE. Fortaleza: Edições Demócrito Rocha, 2002. pp. 219-252.

PEREIRA JÚNIOR, Edilson. O município de Russas no contexto da interiorização da indústria no Ceará. In: VI Encontro Nacional da ANPEGE, 2005, Fortaleza - CE. Anais do VI Encontro Nacional da ANPEGE. Fortaleza: UFC/UECE, 2005. CD-ROM.

PEREIRA JÚNIOR, Edilson e GADELHA, Diego. O novo espaço da produção calçadista no Ceará: o caso do município de Russas. in: ELIAS, Denise. PEQUENO, Luís Renato Bezerra (organizadores). Difusão do agronegócio e novas dinâmicas socioespaciais. Fortaleza: BNB/ETENE, 2006. pp. 435-465.

PIRES, Élson Luciano Silva; VERDI, Adriana Renata. A mobilização dos territórios para o desenvolvimento de arranjos produtivos locais: gênese, aspectos conceituais e bases metodológicas. in: SILVEIRA Márcio Rogério, LAMOSO, Lisandra Pereira; MOURÃO, Paulo Fernando Cirino. Questões nacionais e regionais do território brasileiro. São Paulo: Expressão Popular/UNESP Programa de Pós-Graduação em Geografia, 2009.

RELAÇÃO ANUAL DE INFORMAÇÕES SOCIAIS - RAIS. Base de dados estatísticos. Brasília: RAIS, 2007. CD-ROM.

SANTOS, Milton. O espaço dividido: os dois circuitos da economia urbana dos países subdesenvolvidos. Rio de Janeiro: F. Alves, 1979.

SANTOS, Milton. Circuitos espaciais da produção: um comentário. In: SANTOS, Milton. SOUZA, Maria Adélia. A construção do espaço. São Paulo: Nobel, 1986. pp. 121-134.

SANTOS, Milton. Guerra dos lugares. in: O país distorcido - o Brasil, a globalização e a cidadania. São Paulo: Publifolha, 2002. pp. 87-89.

SOARES, Hidelbrando dos Santos. Agricultura e reorganização do espaço: a rizicultura irrigada em Limoeiro do Norte - CE. Dissertação (Mestrado em Geografia). Universidade Federal de Pernambuco, Recife, 1999.

SOARES, Hidelbrando dos Santos. Agricultura e modernização sócio-espacial em Limoeiro do Norte. In: ELIAS, Denise. SAMPAIO, José Levi Furtado. Modernização excludente. Fortaleza: Edições Demócrito Rocha, 2002.

Trabalho enviado em janeiro de 2010 Trabalho aceito em abril de 2010 